\title{
Hypertension Across the Atlantic: A Sprint or a Marathon?
}

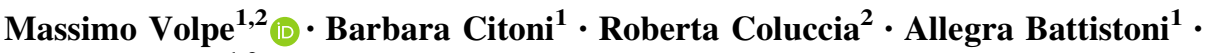 \\ Giuliano Tocci ${ }^{1,2}$
}

Received: 8 April 2017/Accepted: 18 April 2017/Published online: 27 April 2017

(c) Springer International Publishing Switzerland 2017

Last year, in the middle of September, a sudden scientific storm hit North America and the world of hypertension. Somehow unconventionally, the New York Times newspaper announced for the first time in an article for the lay public the surprising results of the Systolic Blood Pressure Intervention Trial (SPRINT) [1], a large, randomized, controlled clinical trial performed under the auspices of the National Institute of Health (NIH) in the United States. The most astonishing part of this article reported the beneficial effects of reaching $120 \mathrm{mmHg}$ of systolic blood pressure (BP). The SPRINT trial was aimed at exploring whether the achievement of an ambitious BP target that was, indeed, $120 \mathrm{mmHg}$ or less for the systolic would bring an advantage in reducing the risk of cardiovascular disease [1]. The benchmark for the comparison was the conventional systolic BP normality threshold of less than 140 $\mathrm{mmHg}$, heralded for more than 10 years as one of the few "mantra" in hypertension in a number of European and North American guidelines sets [2-9]. Definitive scientific results of the trial were finally presented in the Late Breaking Section at the American Heart Association Scientific Sessions and simultaneously published on the New England Journal of Medicine in the middle of November [10].

Some of the very specific features of the population of SPRINT sounded reassuring, at a first sight, for the

Massimo Volpe

massimo.volpe@uniroma1.it

1 Division of Cardiology, Department of Clinical and Molecular Medicine, Faculty of Medicine and Psychology, Sant'Andrea Hospital, University of Rome Sapienza, Rome, Italy

2 IRCCS Neuromed, Pozzilli, IS, Italy hypertension scientific community, in spite of the quite astonishing results. In fact, some of the choices in the features of the population included in the trial had led to a design enrolling only hypertensive patients "crawling" in the high-normal range of systolic BP. Moreover, people with difficult-to-treat hypertension were surprisingly excluded from the trial. Furthermore, the 9361 hypertensive patients enrolled were aged more than 50 years, excluding history of diabetes or prior stroke, though featuring a high cardiovascular risk, as defined by one or more of the following items: clinical or subclinical cardiovascular disease other than stroke, chronic kidney disease, excluding polycystic kidney disease, with an estimated glomerular filtration rate between $20-60 \mathrm{ml} / \mathrm{min} / 1.73 \mathrm{~m}^{2}$ of body surface area, and exceeding $15 \%$ of estimated risk, according to Framingham Score [11].

The main conclusions of the SPRINT investigators were that more aggressive BP reductions would led to beneficial and significant effects on cardiovascular accidents, mostly heart failure and cardiovascular and non-cardiovascular death, compared to conventional BP targets [10]. On the other hand, these results would probably be the subject of a cautious reappraisal next year (2 years after this breakthrough publication of SPRINT trial), with a much more conservative pace (like the one you use in "marathons"). In the meantime, a number of publications raised "lethal" criticisms to SPRINT design, methods and conclusions [12-16]. We must say, for the sake of our readers, that some of these criticisms were appropriate and we decided to list them below.

First of all, the authors of SPRINT, prompted by a not really timely need to measure BP levels in the "best way", adopted in the study protocol a method now defined "unattended measurement of BP levels". According to this methodology, all enrolled patients were left alone in a quiet 
room for $5 \mathrm{~min}$, after which BP measurements automatically started in the absence of treating physician or trained nurse. On the basis of the study protocol, this was chosen as the BP value of the trial. Now, beyond the fact that it is hard to say at this time whether this is better or more reliable than conventional "office BP", it is considered that this BP assessment may produce "artificially lower BP" ranging between 15 to $20 \mathrm{mmHg}$. This, in other words, would mean that the goal of less than $120 \mathrm{mmHg}$ would more or less correspond to less than $140 \mathrm{mmHg}$ and that the goal of less than $140 \mathrm{mmHg}$ would correspond to approximately less than $160 \mathrm{mmHg}$ adopted in the vast majority of recent randomized clinical trials in hypertension [17-20]. Indeed, Myers et al. clearly demonstrated relevant differences between BP values obtained by automated devices and conventional measurements [21]. Now, if this is the case, there is nothing new to show that the lower BP goals would carry a better prognosis than the higher BP target, being this observation consistent with the results of recent trials and meta-analyses [22-25]. The more negative aspect of the choice of the "unattended BP" is that this is the only large clinical trial ever to use this type of BP measurement, thus being not comparable with any other clinical trial on hypertension. Not to say that the "unattended BP" would be simply not realistic to be widely adopted in the clinical practice, being time consuming and not possible in most physicians' offices around the world.

A more recent ancillary analysis was aimed at evaluating the effect of intensive versus standard clinic-based BP targets on 24-h ambulatory BP levels, which were assessed within 3 weeks of the 27-month study visit in 897 patients enrolled in the SPRINT trial [26]. As expected, baseline 24-h, daytime and night-time BP levels at baseline were below the recommended BP thresholds and lower than BP values measured as described above [26]. At the end of the observation, intensive clinic-based treatment arm showed lower night-time, daytime, and 24-h systolic BP levels compared with standard clinic-based treatment arm, although the difference in ambulatory BP between groups was less than the difference measured by clinic BP. In addition, there was no difference in diurnal change in $\mathrm{BP}$ between groups [26].

Second drawback of the SPRINT trial, in our opinion, regards the procedures for drug treatment provided by the study protocol. Indeed, the "standard care" group was forced to stay above $130 \mathrm{mmHg}$, and if BP tended to go below the experimental limit, the Investigators were asked to reduce the pharmacological treatment (number and dosage of drugs) in order to avoid protocol withdrawn. Needless to say that this is an odd, almost unnatural decision. Though we understand the interest of the design and the rigorous approach to answer the questions proposed by the study committee, this behaviour most likely caused disparate treatment choices among the investigators on how to reach this purpose. On the other hand, in the "intensive care" group, instead, the investigators were asked to achieve the predefined BP goals mostly by forcing diuretic therapy (based on the use of chortalidone and loop diuretics). Nevertheless, the target BP of less than 120 $\mathrm{mmHg}$ was achieved in less than a half of the population of the intensive care arm, which indirectly confirms the objective difficulty in reaching more ambitious (or even not tolerated) BP levels.

In this latter regard, many colleagues would ask themselves if this is really the most effective and safe way, especially in the long term, to push-up therapy in most hypertensive patients. In fact, hypotension, syncopal episodes, acute kidney injury, acute renal failure and serum electrolyte abnormalities (lowered sodium and potassium) were more commonly detected in the intensively treated group. We should absolutely not underestimate these adverse effects, given that some authors have shown how acute kidney disease and hypotension are associated with higher morbidity and mortality rates [27, 28]. In particular, we should think about long-term outcomes in elderly patients with hypertension. In fact, low BP could be the cause of falls and impairment of cognitive function in ageing people with a consequent reduction of their quality of life, disability and long term costs of care.

Obviously, using more diuretics in the intensive care arm, whilst reducing use of diuretics in the conventional care arm in order to avoid protocol withdraws, were the major drivers of the benefits observed in the intensive care treatment on the cumulative incidence of the primary endpoint. As it can be expected with the overuse of diuretics, the major protective cardiovascular effect was evident primarily for heart failure $(\mathrm{P}=0.002)$, without significant benefits for myocardial infarction or stroke. Even if it has been already known the strong link between hypertension and the progression of heart failure [29], SPRINT results could be important to guide the choice of an intensive treatment in hypertensive patients with heart failure as a comorbidity.

In spite of these criticisms, that can be mostly shared or not, SPRINT remains today an important study which responds to an important question in the field of hypertension management, that is treating patients with hypertension and high risk profile with the aim to reduce BP to lower levels may bring a definite benefit, especially if this is done in a cautious way.

A recent meta-analysis of other studies [22] also seems to be in favour of the concept "lower is better", which is supported by the SPRINT trial. So, we do need to consider SPRINT as an important piece of evidence, that has to be taken into account wisely in recent hypertension guidelines 
and recommendations, as well as in the clinical practice of hypertensive patients on both sides of the Atlantic Ocean.

Therefore, although the SPRINT results were initially interpreted as applicable only to a limited cohort of hypertensive patients (i.e. the "SPRINT-like" population) and not to the general population of patients with essential hypertension and high cardiovascular risk, these considerations would promote a more extended and irradiated sight of the main findings of the trials. In fact, the clear and significant advantages observed in all endpoints for the group doomed to reach a $120 \mathrm{mmHg}$ versus the group supposed to stay below the classical thresholds of less than $140 / 90 \mathrm{mmHg}$, confirmed in all pre-specified groups, influenced the North America community so much that, for instance, Canadian Guidelines for hypertension were urgently changed, fixing the new target for hypertension treatment to less than $120 \mathrm{mmHg}$ for systolic BP for all patients with essential hypertension [30].

Much more cautious were the almost unanimous comments in Europe, the other side of the Atlantic. Together with a number of articles written by authoritative experts in hypertension, that almost systematically concluded that there is no rush (or "SPRINT") to change or amend current hypertension guidelines, we believe that the main findings of SPRINT trials should be considered as an opportunity for implementing strategies for reducing the burden of hypertension-related cardiovascular diseases in the medium-long term. To achieve this goal, physicians must preserve and properly use their force, like in a marathon, thus avoiding easy and partially justifiable rushes soon after the start.

\section{Compliance with Ethical Standards}

\section{Funding None.}

Conflict of interest Authors have no conflict of interest to disclose with the contents of the present manuscript.

Ethical approval This article does not contain any studies with human participants.

\section{References}

1. Ambrosius WT, Sink KM, Foy CG, Berlowitz DR, Cheung AK, Cushman WC, et al. The design and rationale of a multicenter clinical trial comparing two strategies for control of systolic blood pressure: the Systolic Blood Pressure Intervention Trial (SPRINT). Clin Trials. 2014;11(5):532-46.

2. Mancia G, Fagard R, Narkiewicz K, Redon J, Zanchetti A, Bohm $\mathrm{M}$, et al. $2013 \mathrm{ESH} / \mathrm{ESC}$ Guidelines for the management of arterial hypertension: the Task Force for the management of arterial hypertension of the European Society of Hypertension (ESH) and of the European Society of Cardiology (ESC). J Hypertens. 2013;31(7):1281-357.

3. Mancia G, De Backer G, Dominiczak A, Cifkova R, Fagard R, Germano G, et al. 2007 ESH-ESC Practice Guidelines for the
Management of Arterial Hypertension: ESH-ESC Task Force on the Management of Arterial Hypertension. J Hypertens. 2007;25(9):1751-62.

4. Cifkova R, Erdine S, Fagard R, Farsang C, Heagerty AM, Kiowski W, et al. Practice guidelines for primary care physicians: 2003 ESH/ESC hypertension guidelines. J Hypertens. 2003;21(10):1779-86.

5. James PA, Oparil S, Carter BL, Cushman WC, Dennison-Himmelfarb C, Handler J, et al. 2014 evidence-based guideline for the management of high blood pressure in adults: report from the panel members appointed to the Eighth Joint National Committee (JNC 8). JAMA. 2014;311(5):507-20.

6. Chobanian AV, Bakris GL, Black HR, Cushman WC, Green LA, Izzo JL Jr, et al. Seventh report of the Joint National Committee on Prevention, Detection, Evaluation, and Treatment of High Blood Pressure. Hypertension. 2003;42(6):1206-52.

7. Hackam DG, Quinn RR, Ravani P, Rabi DM, Dasgupta K, Daskalopoulou SS, et al. The 2013 Canadian Hypertension Education Program recommendations for blood pressure measurement, diagnosis, assessment of risk, prevention, and treatment of hypertension. Can J Cardiol. 2013;29(5):528-42.

8. Hackam DG, Khan NA, Hemmelgarn BR, Rabkin SW, Touyz RM, Campbell NR, et al. The 2010 Canadian Hypertension Education Program recommendations for the management of hypertension: part 2-therapy. Can J Cardiol. 2010;26(5):249-58.

9. Khan NA, McAlister FA, Campbell NR, Feldman RD, Rabkin S, Mahon J, et al. The 2004 Canadian recommendations for the management of hypertension: part II-Therapy. Can J Cardiol. 2004;20(1):41-54.

10. Group SR, Wright JT Jr, Williamson JD, Whelton PK, Snyder JK, Sink KM, et al. A randomized trial of intensive versus standard blood-pressure control. N Engl J Med. 2015;373(22): 2103-16.

11. Lloyd-Jones DM, Wilson PW, Larson MG, Beiser A, Leip EP, D'Agostino RB, et al. Framingham risk score and prediction of lifetime risk for coronary heart disease. Am J Cardiol. 2004;94(1):20-4.

12. Kjeldsen SE, Narkiewicz K, Hedner T, Mancia G. The SPRINT study: outcome may be driven by difference in diuretic treatment demasking heart failure and study design may support systolic blood pressure target below $140 \mathrm{mmHg}$ rather than below 120 mmHg. Blood Press. 2016;25(2):63-6.

13. Zanchetti A, Liu L, Mancia G, Parati G, Grassi G, StrambaBadiale M, et al. Continuation of the ESH-CHL-SHOT trial after publication of the SPRINT: rationale for further study on blood pressure targets of antihypertensive treatment after stroke. J Hypertens. 2016;34(3):393-6.

14. Touyz RM, Dominiczak AF. Successes of SPRINT, but still some hurdles to cross. Hypertension. 2016;67(2):268-9.

15. Ewen S, Lobo MD, Pathak A, Schmieder RE, Tsioufis C, Wijns $\mathrm{W}$, et al. Will SPRINT change my practice? SPRINT: a randomised trial of intensive versus standard blood-pressure control. EuroIntervention. 2016;12(6):809-12.

16. Ruilope LM, Banegas JR. SPRINT study in clinical practice: the goal is to change control blood pressure? Hipertens Riesgo Vasc. 2016;33(2):47-50.

17. Dahlof B, Devereux RB, Kjeldsen SE, Julius S, Beevers G, de Faire U, et al. Cardiovascular morbidity and mortality in the Losartan Intervention For Endpoint reduction in hypertension study (LIFE): a randomised trial against atenolol. Lancet. 2002;359(9311):995-1003.

18. Officers A, Coordinators for the ACRGTA, Lipid-Lowering Treatment to Prevent Heart Attack T. Major outcomes in highrisk hypertensive patients randomized to angiotensin-converting enzyme inhibitor or calcium channel blocker vs diuretic: the 
Antihypertensive and Lipid-Lowering Treatment to Prevent Heart Attack Trial (ALLHAT). JAMA. 2002;288(23):2981-97.

19. Julius S, Kjeldsen SE, Weber M, Brunner HR, Ekman S, Hansson $\mathrm{L}$, et al. Outcomes in hypertensive patients at high cardiovascular risk treated with regimens based on valsartan or amlodipine: the VALUE randomised trial. Lancet. 2004;363(9426):2022-31.

20. Dahlof B, Sever PS, Poulter NR, Wedel H, Beevers DG, Caulfield $\mathrm{M}$, et al. Prevention of cardiovascular events with an antihypertensive regimen of amlodipine adding perindopril as required versus atenolol adding bendroflumethiazide as required, in the Anglo-Scandinavian Cardiac Outcomes Trial-Blood Pressure Lowering Arm (ASCOT-BPLA): a multicentre randomised controlled trial. Lancet. 2005;366(9489):895-906.

21. Myers MG, Kaczorowski J, Paterson JM, Dolovich L, Tu K. Thresholds for diagnosing hypertension based on automated office blood pressure measurements and cardiovascular risk. Hypertension. 2015;66(3):489-95.

22. Xie X, Atkins E, Lv J, Bennett A, Neal B, Ninomiya T, et al. Effects of intensive blood pressure lowering on cardiovascular and renal outcomes: updated systematic review and meta-analysis. Lancet. 2016;387(10017):435-43.

23. Ettehad D, Emdin CA, Kiran A, Anderson SG, Callender T, Emberson J, et al. Blood pressure lowering for prevention of cardiovascular disease and death: a systematic review and metaanalysis. Lancet. 2016;387(10022):957-67.
24. Weber MA, Lackland DT. Hypertension: cardiovascular benefits of lowering blood pressure. Nat Rev Nephrol. 2016;12(4):202-4.

25. Thomopoulos C, Parati G, Zanchetti A. Effects of blood pressure lowering on outcome incidence in hypertension: 7. Effects of more vs. less intensive blood pressure lowering and different achieved blood pressure levels - updated overview and metaanalyses of randomized trials. J Hypertens. 2016;34(4):613-22.

26. Drawz PE, Pajewski NM, Bates JT, Bello NA, Cushman WC, Dwyer JP, et al. Effect of intensive versus standard clinic-based hypertension management on ambulatory blood pressure: results from the SPRINT (Systolic Blood Pressure Intervention Trial) Ambulatory Blood Pressure Study. Hypertension. 2017;69(1): $42-50$.

27. Macedo E, Mehta RL. Preventing acute kidney injury. Crit Care Clin. 2015;31(4):773-84.

28. Ricci F, De Caterina R, Fedorowski A. Orthostatic hypotension: epidemiology, prognosis, and treatment. J Am Coll Cardiol. 2015;66(7):848-60.

29. Tocci G, Sciarretta S, Volpe M. Development of heart failure in recent hypertension trials. J Hypertens. 2008;26(7):1477-86.

30. Leung AA, Nerenberg K, Daskalopoulou SS, McBrien K, Zarnke KB, Dasgupta K, et al. Hypertension Canada's 2016 Canadian Hypertension Education Program Guidelines for Blood Pressure Measurement, Diagnosis, Assessment of Risk, Prevention, and Treatment of Hypertension. Can J Cardiol. 2016;32(5):569-88. 